\title{
Convergent Findings for Abnormalities of the NF- $\kappa$ B Signaling Pathway in Schizophrenia
}

\author{
Panos Roussos',2, Pavel Katsel', Kenneth L Davis', Stella G Giakoumaki ${ }^{3,4}$, Larry J Siever ${ }^{1,2}$, \\ Panos Bitsios ${ }^{3}$ and Vahram Haroutunian*,, ,2 \\ 'Department of Psychiatry, The Mount Sinai School of Medicine, New York, NY, USA; ${ }^{2}$ J Peters VA Medical Center, Bronx, NY, USA; \\ ${ }^{3}$ Department of Psychiatry and Behavioral Sciences, Faculty of Medicine, University of Crete, Heraklion, Crete, Greece; ${ }^{4}$ Department of \\ Psychology, University of Crete, Rethymno, Greece
}

\begin{abstract}
Neurons exhibit a constitutive level of nuclear factor- $\kappa \mathrm{B}(\mathrm{NF}-\kappa \mathrm{B})$ signaling and this pathway plays a significant role in neurite outgrowth, activity-dependent plasticity, and cognitive function. Transcription factor analysis was performed in a microarray data set profiled in four different brain regions ( $n=54$ comparison group; $n=53$ schizophrenia (SZ)). An independent postmortem cohort was used for gene expression ( $n=24$ comparison group; $n=22 \mathrm{SZ}$ ), protein abundance $(n=8$ comparison group; $n=8 \mathrm{SZ}$ ), and NF- $\kappa \mathrm{B}$ nuclear activity ( $n=10$ comparison group; $n=10 \mathrm{SZ}$ ) quantification. Expression quantitative trait locus analysis was performed using publicly available data. Prepulse inhibition (PPI) of the acoustic startle reflex was tested in healthy individuals $(n=690)$. Comparison of microarray data showed that NF- $\kappa$ B was among the transcription factors associated with the differential expression of genes in cases vs controls. NF- $\kappa \mathrm{B}$ gene and protein levels and nuclear activation were significantly decreased in the superior temporal gyrus of patients with SZ. Upstream $\mathrm{NF}-\kappa \mathrm{B}$ genes related to translocation were significantly dysregulated in SZ. The gene expression levels of an NF- $\kappa \mathrm{B}$-associated importin (KPNA4: one of the proteins responsible for the translocation of NF- $\kappa$ B to the nucleus) was decreased in SZ and an SNP within the KPNA4 locus was associated with susceptibility to SZ, reduced KPNA4 expression levels and attenuated PPI of the startle reflex in healthy control subjects. These findings implicate abnormalities of the NF- $\kappa$ B signaling pathway in SZ and provide evidence for an additional possible mechanism affecting the translocation of NF- $\kappa$ B signaling to the nucleus.

Neuropsychopharmacology (2013) 38, 533-539; doi:I0.I038/npp.20I2.2I5; published online 7 November 2012
\end{abstract}

Keywords: postmortem; mRNA; superior temporal gyrus; prepulse inhibition; importin; transcription factor

\section{INTRODUCTION}

The nuclear factor- $\kappa \mathrm{B}(\mathrm{NF}-\kappa \mathrm{B})$ signaling pathway has been recognized as an important regulator of the growth and morphology of neural processes in the developing and mature nervous system (Gutierrez and Davies, 2011). Diverse extracellular signals activate NF- $\kappa \mathrm{B}$, including inflammatory cytokines, such as TNF- $\alpha$, neurotrophic factors such as brain-derived neurotrophic factor (BDNF) and nerve growth factor, the excitatory neurotransmitter glutamate, and cell adhesion molecules (Gutierrez and Davies, 2011). NF- $\kappa \mathrm{B}$ is constitutively activated in neurons, regulating the expression of an increasingly recognized number of genes involved in cell survival, synaptic plasticity, and memory in the adult brain (Gutierrez and Davies, 2011).

The NF- $\kappa$ B family of transcription factors consists of five members: p65 or RELA, p50, p52, c-REL, and RELB, which

*Correspondence: Dr $\vee$ Haroutunian, Department of Psychiatry, The Mount Sinai School of Medicine, Room 4F-33, 130 West Kingsbridge Road, New York, Bronx, NY 10468, USA, Tel: + I 7185849000 ext 6082, Fax: + 17183659622 ,

E-mail: vahram.haroutunian@mssm.edu

Received 28 August 2012; revised 3 October 2012; accepted 4 October 2012 interact with each other by forming heterodimers or homodimers. In resting cells, NF- $\kappa$ B dimmers are normally kept in an inactive state by association with proteins of the NF- $\kappa$ B inhibitor family (I $\kappa$ B) (Perkins, 2007). In neurons, the most prominent heterodimer is the p65 and p50 complex, which is inactive in the cytoplasm when bound to $\mathrm{I} \kappa \mathrm{B} \alpha$ (Gutierrez and Davies, 2011). However, other complexes are present in neurons and their subunit composition may vary depending on factors such as the developmental state and the location of neurons within the nervous system (Gutierrez and Davies, 2011). Activation of the canonical NF- $\kappa$ B pathway is controlled by the $I \kappa B$ kinase (IKK) complex. Following cell stimulation, the IKK complex phosphorylates $\mathrm{I} \kappa \mathrm{B}$ proteins on specific serine residues and targets $\mathrm{I} \kappa \mathrm{B}$ to polyubiquitination and proteasomal degradation liberating the NF- $\kappa \mathrm{B}$ complex. The $\mathrm{NF}-\kappa \mathrm{B}$ dimmers translocate to the nucleus through interactions with importins, such as $\alpha 3$ and 4 (Fagerlund et al, 2005), and activate gene transcription by binding to $\kappa \mathrm{B}$ sites in promoters of target genes.

There is growing evidence supporting a role for NF- $\kappa \mathrm{B}$ in schizophrenia (SZ). First, NF- $\kappa$ B is activated by cytokines, neurotrophic factors, such as BDNF and glutamate, which have been strongly associated with SZ (for review see 
Buckley et al, 2011; Dean, 2011; Javitt et al, 2011; Watanabe et al, 2010). Second, first-episode, drug naive, schizophrenic patients show higher levels of cytokines in the serum and NF- $\kappa \mathrm{B}$ activation (increased RELA gene expression and $\mathrm{p} 65$ nuclear activity) in peripheral blood mononuclear cells (Song et al, 2009). Third, pathway analysis using SZ candidate genes identified NF- $\kappa \mathrm{B}$ as a hub, where multiple, diverse signal transduction pathways, enriched for SZ genetic risk factors, converge (Sun et al, 2010). Fourth, a recent study reported a genetic association for the RELA gene and in silico analysis suggested that the $\mathrm{SZ}$ risk genetic variants were associated with downregulation of RELA (Hashimoto et al, 2011).

The current studies were undertaken to advance the observation of NF- $\kappa \mathrm{B}$ gene and protein expression abnormalities in SZ and explore further mechanisms of NF- $\kappa \mathrm{B}$ regulation of transcriptional machinery. Exploratory analysis of data from a large postmortem microarray study of multiple brain regions of persons with SZ suggested downregulation of the NF- $\kappa \mathrm{B}$ complex, as well as, alterations in the expression levels of upstream genes important for the activation and translocation of the NF- $\kappa \mathrm{B}$. The involvement of the NF- $\kappa$ B genes and proteins in SZ was more directly identified by analysis of postmortem brain tissue from an independent cohort of persons with SZ and unaffected comparison controls. Molecular (gene expression), cognitive (prepulse inhibition (PPI) of the acoustic startle reflex), and clinical data were used to examine whether genetic variants influence the NF- $\kappa \mathrm{B}$. In silico and genetic association studies identified a genetic variant in an importin gene that is associated with increased risk for SZ, reduced expression of the importin gene, and attenuated PPI of the acoustic startle reflex in human subjects.

\section{MATERIALS AND METHODS}

\section{Postmortem Cohort}

Brain tissue specimens were derived from the Brain Bank of the Department of Psychiatry of the Mount Sinai School of Medicine (New York, NY)/JJ Peters VA Medical Center (Bronx, NY). Total RNA was extracted from $50 \mathrm{mg}$ of frozen tissue and gene expression was determined using the Affymetrix Human Genome U133 Plus 2.0 arrays (Santa Clara, CA) or quantitative polymerase chain reaction (qPCR). For the microarray analysis gray matter from dorsolateral prefrontal cortex (Brodmann area (BA) 46), middle temporal area gyrus (BA21), temporopolar area (BA38), and anterior cingulate cortex (BA32) from $21 \mathrm{SZ}$ cases and 19 controls was used, as described in detail previously (Roussos et al, 2012b). Gray matter from the superior temporal gyrus (STG) and primary visual cortex (PVC) were used in qPCR analysis in an independent set of brain tissue specimens (22 SZ cases and 24 controls), similarly to previous studies (Roussos et al, 2012a) (Supplementary File). TaqMan probe ID's are listed in Supplementary Table 1. Similarly prepared sister aliquots from STG were used in quantitative western blotting $(n=8$ per group) and NF- $\kappa$ B activation assay ( $n=10$ per group). Supplementary Table 2 shows the characteristics of the different postmortem cohorts used in the current study.

\section{Healthy Individuals}

We examined the association of the importin $\alpha 3$ gene (KPNA4) rs4130284 with PPI of the acoustic startle reflex in 690 individuals from the LOGOS (Learning On Genetics Of SZ Spectrum) cohort, which has been described in detail previously (Roussos et al, 2011a,b). The Caucasian ancestry of these subjects was confirmed based on EIGENSOFT analysis (Patterson et al, 2006; Price et al, 2006) of genomewide genotyping SNP profiling with the Illumina HumanOmniExpress BeadChip (San Diego, CA).

\section{Quantitative Western Blotting}

Blots were probed with rabbit anti-p65 polyclonal antibody (1:500 v/v dilution; Abcam, Cambridge, MA) and mouse anti-GAPDH antibody (1:10000 v/v dilution, Meridian Life Science, Saco, ME). Visualization and quantification of bands were performed with the Odyssey 2.1 software (Li-COR Biosciences, Lincoln, NE). To account for gel to gel variability, the relative expression value of p65 and GADPH in each sample was calculated as a ratio between the averaged intensities of the band in the experimental sample and in the 'standard-calibrator' (a mix of small aliquots of tissue from all samples run in parallel lanes).

\section{NF- $\boldsymbol{\kappa} B$ Activation Assay}

Activation of the p65 subunit of NF- $\kappa$ B was determined using an NF- $\kappa \mathrm{B}$ chemiluminescent DNA-binding enzymelinked immunosorbent assay (ELISA) kit (TransAM ${ }^{\mathrm{TM}}$ NF $\kappa$ B Chemi Kits; Active Motif, Carlsbad, CA) according to the manufacturer's protocol in nuclear extracts from STG. The NF- $\kappa$ B detecting antibody recognizes an epitope on p65 that is accessible only when NF- $\kappa \mathrm{B}$ is activated (Renard et al, 2001).

\section{Chronic Haloperidol Studies in Rats}

To assess the effects of neuroleptic exposure on the expression of selected genes of interest, groups of eight male Sprague-Dawley rats (6-8 months of age) received daily subcutaneous injections of haloperidol $(2 \mathrm{mg} / \mathrm{kg})$ or saline vehicle for 21 days. Rela and $N f k b 1$ expression was assessed by qPCR using rat-specific primers and probes (Supplementary Table 1).

\section{Statistical Data Analysis}

Transcription factor analysis was carried out using the Ingenuity Pathway Analysis (IPA) (www.ingenuity.com) (Redwood City, CA). This analysis is based on literaturederived evidence on the directional ('activated' or 'inhibited') downstream influence of transcription factors on the expression level of transcripts included in experimentally derived gene expression data set. If the direction of change in the expression of a gene is consistent with the literature across most targets, IPA predicts that the transcription factor is more active in the experimental sample than in the control. If the direction of change is mostly inconsistent with the literature, IPA predicts that the transcription factor is less active in the experimental sample 
than in the control. This analysis approach predicts a $Z$-score based on transcriptional regulators that are able to explain observed gene expression changes and infer their activation state. The $Z$-score determines whether an upstream transcription regulator has significantly more 'activated' predictions than 'inhibited' predictions $(z>0)$ or vice versa $(z<0)$.

Expression quantitative trait loci (eQTL) analysis was conducted in the BrainCloud data set $(n=268)$ (http:// braincloud.jhmi.edu) (Colantuoni et al, 2011) using linear regression models for SNPs located within $1 \mathrm{Mb}$ of the transcript being tested (cis-eQTL). The Psychiatric Genomics Consortium GWAS results in SZ (Ripke et al, 2011) were visualized using ricopili (http://www.broadinstitute.org/mpg/ricopili/). A two-tailed Student's $t$-test was used to compare relative mRNA expression of NF- $\kappa \mathrm{B}$ in $\mathrm{qPCR}$, relative abundance of $\mathrm{p} 65$ protein and p65 activation assay. For multiple testing corrections in the mRNA gene expression comparisons, adjusted $P$-values were calculated based on 1000 permutations. A genotype by prepulse by interval ANOVA was used for PPI comparison in the LOGOS cohort. Student's $t$-test and ANOVA were performed using SPSS (version 20; IBM, Armonk, NY).

\section{RESULTS}

Microarray Data Set Analysis Suggests Downregulation of the NF- $\kappa$ B Pathway in SZ

The IPA transcription factor analysis was used in order to identify the transcription factors that are responsible for gene expression changes in a microarray data set from a recently published study (Roussos et al, 2012b). Given the observed gene expression changes in the experimental data set, the NF- $\kappa \mathrm{B}$ (complex) and RELA were predicted to be downregulated in $\mathrm{SZ}$ in all brain regions whether examined separately or in total (Table 1). The specificity of the analysis is indicated by the fact that across all brain regions, out of 320 significant transcription factors (overlap $P$-value $<0.05$ ), only 39 were predicted with specific directionality (12 activated and 27 inhibited). The NF- $\kappa \mathrm{B}$ (complex) was the most significant (lowest $Z$-score) inhibited transcription regulator in this data set. Furthermore, the majority of the $\mathrm{NF}-\kappa \mathrm{B}$ signaling genes were downregulated in the microarray data set (Supplementary Figure 2).

\section{Confirmation of Gene Expression Changes of NF- $\kappa \mathrm{B}$ Complex in STG by qPCR}

Genes that encode the most prominent proteins of NF- $\kappa \mathrm{B}$ complex (NFKB1, RELA, and NFKBIA) or are involved in the NF- $\kappa \mathrm{B}$ signaling pathway (MAP3K7) in the STG and PVC were selected for qPCR analysis in a cohort of cases and controls. In the STG, the RELA (adjusted $P=0.021$; $\mathrm{FC}=-1.56$ ) and $M A P 3 K 7$ (adjusted $P=0.01 ; \mathrm{FC}=-1.36$ ) genes were significantly downregulated in SZ (Table 2). Similar changes were not observed in the PVC. Sample pH, PMI, or age of the donors did not correlated significantly with gene expression levels. ANCOVAs analysis with age, sex, $\mathrm{pH}, \mathrm{RIN}$, and smoking status as covariates did not change the results (Table 2). Similarly, Rela and Nfkb1 mRNA expression levels were not altered in rats treated with haloperidol for 3 weeks vs vehicle ( $P$-values $>0.7$ in both comparisons).

\section{Decreased p65 Protein Levels and Nuclear Activation in STG of Individuals with SZ}

To further explore the decreased RELA expression levels in STG, the p65 protein levels ( $n=8$ per group) and nuclear activation ( $n=10$ per group) were measured in samples from individuals with SZ vs controls (Supplementary Table 1). Samples from patients with SZ had decreased p65 protein levels $(P=0.009)$ (Figure 1a) and reduced p65 nuclear activation $(P=0.009)$ (Figure 1b). ANCOVAs analysis with age, sex, $\mathrm{pH}$, and smoking status as covariates did not change the results for p65 protein levels $(P=0.017)$ or nuclear activation $(P=0.036)$.

\section{Upstream RELA Genes Are Significantly Altered in SZ}

Using the IPA gene data sets, we generated a list of genes (Supplementary Table 3) that affect the activation, activity, binding, expression, phosphorylation, and translocation of RELA and examined whether these genes exhibited altered gene expression. Overall, a significant proportion of the RELA upstream genes (29 out of 117 total transcripts) showed significant $(P<0.05)$ changes in the microarray data set (Supplementary Figure 1; Supplementary Table 3). Genes related to translocation (15 out of 35 total transcripts) and phosphorylation (11 out of 30 total transcripts) showed the most significant alterations in the microarray data set, while genes related to binding and activation were the least affected in the microarray data set (Supplementary Table 3).

\section{The Importin $\propto 3$ Gene (KPNA4) is Significantly Downregulated in SZ}

Given the significant changes in the upstream genes related to translocation and the important role of importins in the translocation of the p65 protein in and out of the nucleus

Table I The IPA Transcription Factor Analysis Identified the NF- $\kappa$ B (Complex) and RELA Transcription Factors as Inhibited Based on the Gene Expression Changes in the Microarray Data Set

\begin{tabular}{|c|c|c|c|c|c|c|c|c|}
\hline \multirow[t]{2}{*}{$\begin{array}{l}\text { Transcription } \\
\text { Factor }\end{array}$} & \multirow[t]{2}{*}{$\begin{array}{l}\text { Target molecules } \\
\text { in data set }\end{array}$} & \multirow[t]{2}{*}{$\begin{array}{l}\text { P-value } \\
\text { overlap }\end{array}$} & \multirow[t]{2}{*}{$\begin{array}{l}\text { Predicted activation } \\
\text { state }\end{array}$} & \multicolumn{5}{|c|}{$\begin{array}{l}\text { Z-score (number of genes with } \\
\text { predicted inhibition) }\end{array}$} \\
\hline & & & & All regions & BA2I & BA32 & BA38 & BA46 \\
\hline $\mathrm{NF}-\kappa \mathrm{B}$ (complex) & 246 & $8.9 \times 10^{-16}$ & Inhibited & $-4.9(119)$ & $-3.5(110)$ & $-3.5(109)$ & $-5.0(123)$ & $-2.6(113)$ \\
\hline RELA & 125 & $1.7 \times 10^{-14}$ & Inhibited & $-2.2(48)$ & $-1.7(46)$ & $-1.8(48)$ & $-1.9(48)$ & $-1.0(47)$ \\
\hline
\end{tabular}


Table 2 qPCR Analysis of Genes Implicated in the NF- $\kappa$ B Signaling in the STG and PVC in Controls $(n=24)$ and Cases with SZ (N=22)

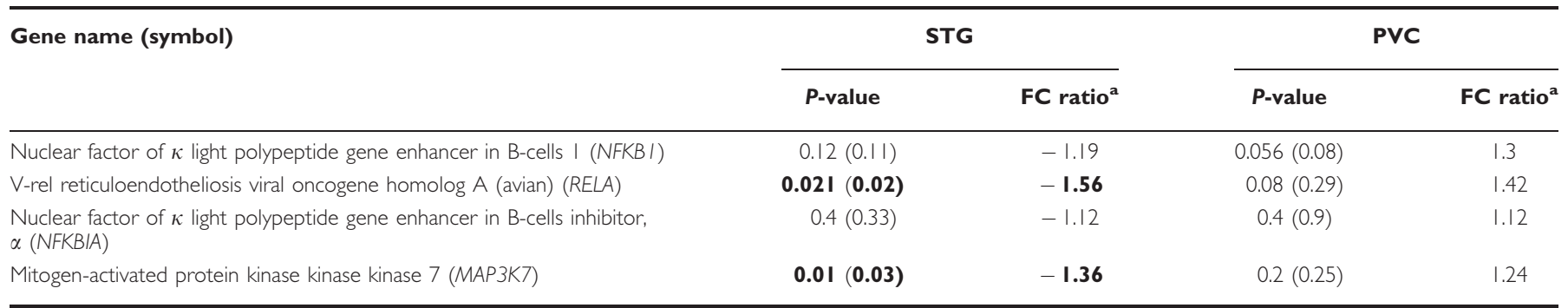

${ }^{\mathrm{a}} \mathrm{FC}$ ratio-fold change ratios represent the ratio of geometric means for each gene to the three housekeeping genes in SZ/control $(+)$ and in control/SZ $(-)$ values. Differentially changed genes $(P<0.05)$ are highlighted in bold. Adjusted $P$-values calculated based on 1000 permutations are shown. In parenthesis are the $P$-values calculated using ANCOVAs with $\mathrm{pH}$, age, sex, and RIN as covariates.
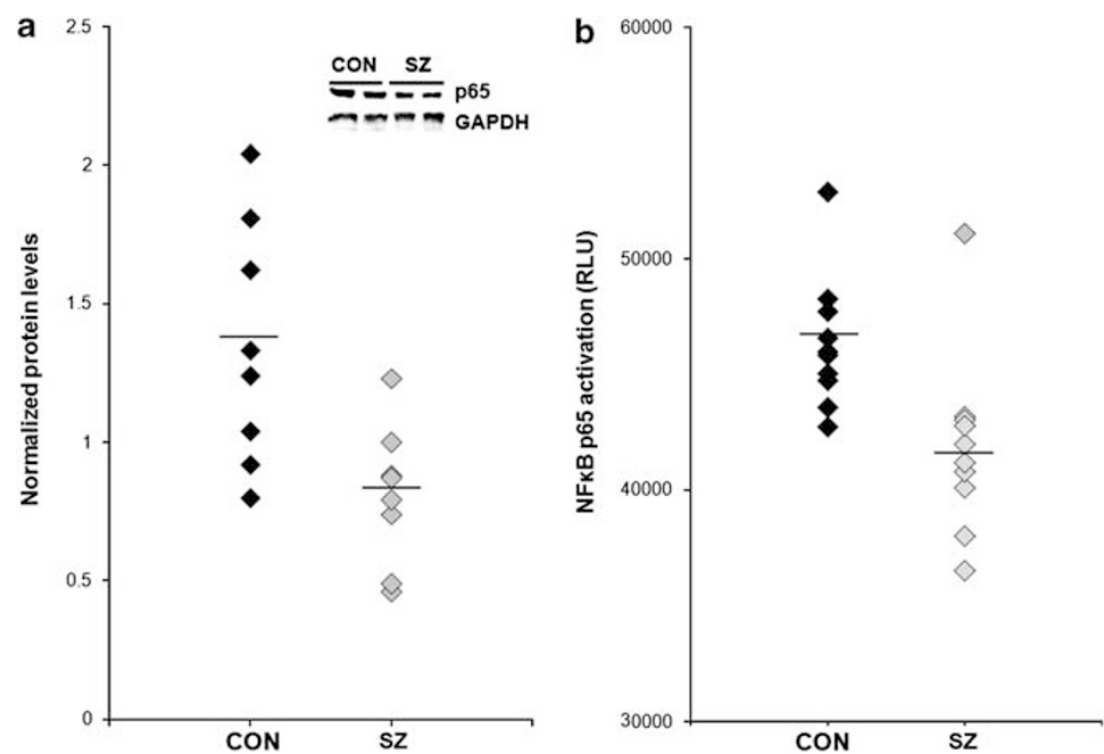

Figure I (a) Western blot quantification of p65 relative abundance in the STG. Individuals with SZ have decreased p65 levels compared with control subjects $(p=0.009)$. Data are expressed as means of $p 65$ ODs normalized to GAPDH and to the amount of total protein $(n=8$ per group). (b) NF- $\kappa B$ p65 nuclear activation in the STG. Individuals with SZ have decreased p65 nuclear activity compared with control subjects $(P=0.009)(n=10$ per group). RLU, relative light unit. Horizontal line displays the group means.

(Fagerlund et al, 2005), we examined in the qPCR cohort whether importin $\alpha 3$ (karyopherin $\alpha 4$ - KPNA4) and $\alpha 4$ (karyopherin $\alpha 3-K P N A 3$ ) gene expression is altered in SZ. In the STG, KPNA4 (adjusted $P=0.016 ; \mathrm{FC}=-1.23$ ) was significantly downregulated, while a trend was observed for KPNA3 (adjusted $P=0.1 ; \mathrm{FC}=-1.15$ ). No changes were found in the PVC (all adjusted $P$-values $>0.3$ ).

\section{In Silico Expression Quantitative Trait Locus Analysis Identifies KPNA4 as a Susceptible Gene}

Using a hypothesis-driven approach, we screened for RELA, KPNA3, and KPNA4 eQTLs using the BrainCloud data set (Colantuoni et al, 2011). Two cis-eQTLs (rs6793037 and rs4130284) were identified for KPNA4 at $P<10^{-3}$. Based on publicly available results from recent genome-wide association study (GWAS) in SZ (Ripke et al, 2011), rs4130284 was statistically associated with $\mathrm{SZ}(P=0.002$; odds ratio $(\mathrm{OR}) \pm$ confidence interval $(\mathrm{CI}): 1.13 \pm 0.04)$ while rs6793037 was not associated $(P=0.36$; OR \pm CI:
$1.03 \pm 0.03)$. rs 4130284 demonstrated the same directional effect on gene expression and SZ susceptibility. More specifically, the rs4130284 $\mathrm{T}$ allele, that increases the risk for SZ, was associated with reduced KPNA4 expression $(P=0.0004)$ (Supplementary Figure 3$)$, as predicted based on the qPCR gene expression findings (KPNA4 was significantly downregulated in $\mathrm{SZ}$-adjusted $P=0.016$ ).

\section{The KPNA4 rs4130284 T Allele is Associated with Reduced PPI}

There were no differences in demographic and startle variables between the three genotype groups $(\mathrm{C} / \mathrm{C}, \mathrm{C} / \mathrm{T}$, and $\mathrm{T} / \mathrm{T}$ ) (Supplementary Table 4). A mixed-model ANOVA of PPI with genotype as the grouping factor (three levels) and prepulse and interval as the within-subject factors revealed significant main effects of genotype $[\mathrm{F}(2,687)=4.32$, $\left.P=0.014, \quad \eta^{2}=0.012\right]$. Post hoc comparisons with the Tukey's HSD (Honestly Significant Difference) test correction revealed that PPI of the $\mathrm{C} / \mathrm{C}$ group was greater at a 
trend level than PPI of the $\mathrm{C} / \mathrm{T}$ group $(P=0.1)$ and the $\mathrm{T} / \mathrm{T}$ group $(P=0.075)$. When carriers for the minor allele $(\mathrm{T}$ allele: $\mathrm{C} / \mathrm{T}$ and $\mathrm{T} / \mathrm{T}$ subjects) were grouped together, a significant main effects of genotype $[\mathrm{F}(1,688)=5.56$, $\left.P=0.019, \eta^{2}=0.008\right]$ was observed in the mixed-model ANOVA, where carriers of the risk allele had reduced PPI compared with $\mathrm{C} / \mathrm{C}$ subjects. Results were not altered when age, education, smoking status (cigarettes/day), and/or baseline startle were entered as covariates.

\section{DISCUSSION}

These results point to an abnormality in the expression of genes and proteins associated with the NF- $\kappa \mathrm{B}$ signaling pathway in SZ. The gene expression results are strengthened by replication in two independent cohorts using diverse methods. Analysis of microarray data from four different brain regions showed that $\mathrm{NF}-\kappa \mathrm{B}$ signaling is overall inhibited and partially explains some of the downstream alterations in the gene expression found in elderly patients with SZ. The involvement of NF- $\kappa \mathrm{B}$ signaling genes, protein, and nuclear activation assay in SZ was directly tested in postmortem brain tissue from an independent and larger sample of well-matched cases and controls. We found consistent lower expression of NF- $\kappa \mathrm{B}$-related genes and p65 protein, as well as decreased p65 nuclear activation, validating and extending the microarray findings. Furthermore, significant enrichment of altered genes based on the microarray analysis was observed for upstream regulators of the NF- $\kappa \mathrm{B}$ signaling. Genes related to translocation showed the most prominent changes and based on these findings we further tested, in a hypothesis-driven approach, whether importins are altered in SZ. The gene expression of KPNA4 was decreased in SZ and the T allele of the rs4130284 SNP was associated with attenuated KPNA4 expression levels, disrupted PPI of the startle reflex and risk for SZ.

The NF- $\kappa \mathrm{B}$ signaling pathway is ubiquitously expressed, but it has been studied most extensively in the immune system where it regulates a myriad of important physiological processes including immune and inflammatory responses, cell survival, and cell proliferation (Vallabhapurapu and Karin, 2009). However, growing evidence support an additional important role of $\mathrm{NF}-\kappa \mathrm{B}$ in the developing and mature nervous system (Gutierrez and Davies, 2011). More specifically, NF- $\kappa \mathrm{B}$ has important role in controlling axon initiation (Sanchez-Ponce et al, 2008), elongation (Sanchez-Ponce et al, 2008), guidance (Mindorff et al, 2007), and branching (Gavalda et al, 2009) and in regulating dendritic arbor size and complexity during development (Chacon et al, 2010; Li et al, 2010; SalamaCohen et al, 2005) and dendritic spine density in the adult (Christoffel et al, 2011; Russo et al, 2009). Furthermore, $\mathrm{NF}-\kappa \mathrm{B}$ is involved in other important functions including the regulation of neurogenesis in the embryo and adult (Denis-Donini et al, 2008; Koo et al, 2010; Young et al, 2006), cell survival in certain populations of peripheral and central neurons (Li et al, 2000) and promoting peripheral nerve myelination (Nickols et al, 2003). In the mature nervous system, a substantial body of evidence has implicated NF- $\kappa$ B as an important factor for fear conditioning, spatial memory, synaptic plasticity, and long-term memory (Dash et al, 2005; Freudenthal et al, 2005; Yeh et al, 2002). Given the above important functions that NF- $\kappa \mathrm{B}$ subserves in the developing and adult brain, it is plausible that NF- $\kappa \mathrm{B}$ signaling dysregulation can affect critical processes during neurodevelopment that increases susceptibility for SZ. This notion is further supported by the role of cytokines, neurotrophic factors, such as BDNF, and glutamate as activators of NF- $\kappa \mathrm{B}$ signaling, which have all been associated with SZ (for review see Buckley et al, 2011; Dean, 2011; Javitt et al, 2011; Watanabe et al, 2010).

We found downregulation of KPNA4 in the STG of persons with SZ, an important protein that mediates nuclear translocation of the RELA (Fagerlund et al, 2005). While a variety of stimuli activate NF- $\kappa \mathrm{B}$ via several distinct pathways, KPNA4-mediated translocation of NF- $\kappa \mathrm{B}$ is a convergent mechanism that is required as part of the NF- $\kappa \mathrm{B}$ cascade. The nuclear translocation is a highly regulated process and a necessary mechanism to overcome the unique spatiotemporal challenges of neuronal cells. More specifically, long-range signaling from axon terminals to the nucleus is critical during long-lasting forms of synaptic plasticity (Perry and Fainzilber, 2009). In this study we provide evidence not only for RELA and KPNA4 down regulation, but also for a genetic locus that might influence this process by affecting KPNA4 abundance, leading to disrupted PPI, a robust intermediate phenotype for SZ (Braff, 2011; Roussos et al, 2008a,b, 2009, 2011a,b), and increased vulnerability for SZ. Thus, importin-mediated NF- $\kappa \mathrm{B}$ transport in neurons provides an additional mechanism explaining the reduced p65 nuclei activity in patients with SZ. However, our genetic finding should be interpreted with caution for two reasons. First, in the original hypothesis-free GWAS (Ripke et al, 2011), the genetic association did not reach genome-wide level of significance. Second, the rs4130284 is located $336 \mathrm{~kb}$ downstream of the KPNA4 locus. Nevertheless, our a priori hypothesis-driven postmortem brain-based genetic association study that eliminates the necessity for multiple testing correction, the convergent genetic association findings with the same allelic directionality among different cohorts and previous findings describing distant $(>100 \mathrm{~kb})$ cis-eQTL effects (Schadt et al, 2008), provide evidence for the robustness of our findings. However, future studies should replicate these findings.

To our knowledge this is the first study assessing the NF$\kappa \mathrm{B}$ signaling pathway in postmortem tissue of patients with SZ. A recent study found activation of NF- $\kappa \mathrm{B}$ signaling in the peripheral blood of first-episode, drug naive, SZ patients (Song et al, 2009). The opposite results observed in our study might be secondary to $\mathrm{NF}-\kappa \mathrm{B}$ pathway assessment in different tissue and stage of illness. NF- $\kappa \mathrm{B}$ signaling involves a very complex pathway and changes observed in peripheral blood might not reflect $\mathrm{NF}-\kappa \mathrm{B}$ activity in the central nervous system. Furthermore, Song et al included first-episode patients who were moderately to markedly ill, while our study included chronic patients with SZ. Multiple studies have shown that compared with first-episode, chronic patients demonstrate more prominent deficits in outcome variables related to cognition, brain volume, and connectivity (Chan et al, 2011; Ellison-Wright et al, 2008; Friedman et al, 2008; Salisbury et al, 2002). Although 
speculative, NF- $\kappa \mathrm{B}$ signaling might be activated in acute psychotic patients followed by reduction with sustained chronicity. This pathway might represent a compensatory mechanism which fails during the course of illness with reduction of expression levels, leading to deficits in synaptic plasticity. Chronic, phasic activation of the pathway during decompensation of illness might lead to resistance and overall downregulation in later stages. Another recent study reported a genetic association of RELA with SZ and PPI deficits in a Japanese population (Hashimoto et al, 2011). In silico eQTL analysis revealed that the SZ risk genetic variants affect RELA gene expression in immortalized B-lymphocytes. While these findings indicate that RELA will be downregulated in SZ, in this study we failed to identify a strong eQTL effect in human brain tissue. A shortcoming of the current study is a lack of a theoretical framework that incorporates alterations in the $\mathrm{NF}-\kappa \mathrm{B}$ signaling pathway and the core features of SZ. As the holes in our knowledge and the NF- $\kappa \mathrm{B}$ signaling pathway become filled, the development of a data-driven theoretical framework will become more realistic.

Several factors may affect the quality of RNA and proteins, and DNA-binding activities of transcription factors in postmortem human tissues. Neuroleptic exposure is a confounding factor in postmortem studies of $\mathrm{SZ}$ and therefore can contribute to the detected gene expression abnormalities of the NF- $\kappa \mathrm{B}$ signaling pathway. In vivo, haloperidol $(1 \mathrm{mg} / \mathrm{kg})$ treatment for 21 days did not modify the nigral expression of the p65 subunit while clozapine $(1 \mathrm{mg} / \mathrm{kg}$ ) reduced p65 expression as quantified by western blotting (Saldana et al, 2006). Lower dose of haloperidol $(1 \mathrm{mg} / \mathrm{kg})$, clozapine (5 and $10 \mathrm{mg} / \mathrm{kg})$, or risperidone $(5 \mathrm{mg} / \mathrm{kg})$ did not alter NF- $\kappa \mathrm{B}$ expression, while higher doses of haloperidol ( 2 and $5 \mathrm{mg} / \mathrm{kg}$ ), increased p65 activation in nuclear lysates of the brains of rats treated for 21 days (Bishnoi et al, 2008a,b). Finally, haloperidoltreated rats $(1 \mathrm{mg} / \mathrm{kg})$ for 1 week increased p65 DNAbinding activity in hippocampus and caudate putamen (Post et al, 2002). In general, although results among different studies are inconsistent, there is an overall effect of antipsychotic for either increase or no alteration of the p65 activity in rats treated chronically with neuroleptics. Our findings in the cortices of rats are consistent with no changes of Rela and $N f k b 1$ expression levels, further supporting the conclusion that the present findings are not secondary to chronic exposure to neuroleptics. However, the possibility of antipsychotic medication exposure confounds cannot be ruled out entirely, as haloperidol exposure of rats might not mimic the neuroleptic-induced changes in the brain of patients with SZ accurately. One additional limitation of our study is the small number of samples used for the p65 protein quantification and nuclear activation.

Collectively, these findings identify SZ-associated abnormalities in NF- $\kappa \mathrm{B}$ genes and proteins. Adaptations in the NF- $\kappa$ B system may be essential for persistent neuroplastic changes underlying SZ and associated impairment of cognitive functions. While these adaptations may be induced through several mechanisms, we provide evidence for a possible genetic and neurobiological mechanism affecting the translocation of NF- $\kappa \mathrm{B}$ signaling that might be among the keys to the pathophysiology of SZ and to the development of targeted therapeutic interventions.

\section{ACKNOWLEDGEMENTS}

These studies were supported by NIH Grants MH066392, MH064673 to VH and Veterans Administration MIRECC and Merit awards to LS and VH, respectively.

\section{DISCLOSURE}

The authors declare no conflict of interest.

\section{REFERENCES}

Bishnoi M, Chopra K, Kulkarni SK (2008a). Activation of striatal inflammatory mediators and caspase- 3 is central to haloperidolinduced orofacial dyskinesia. Eur J Pharmacol 590: 241-245.

Bishnoi M, Chopra K, Kulkarni SK (2008b). Differential striatal levels of TNF-alpha, NFkappaB p65 subunit and dopamine with chronic typical and atypical neuroleptic treatment: role in orofacial dyskinesia. Prog Neuropsychopharmacol Biol Psychiatry 32: 1473-1478.

Braff DL (2011). Gating in schizophrenia: from genes to cognition (to real world function?). Biol Psychiatry 69: 395-396.

Buckley PF, Pillai A, Howell KR (2011). Brain-derived neurotrophic factor: findings in schizophrenia. Curr Opin Psychiatry 24: 122-127.

Chacon PJ, Arevalo MA, Tebar AR (2010). NGF-activated protein tyrosine phosphatase $1 \mathrm{~B}$ mediates the phosphorylation and degradation of I-kappa-Balpha coupled to NF-kappa-B activation, thereby controlling dendrite morphology. Mol Cell Neurosci 43: 384-393.

Chan RC, Di X, McAlonan GM, Gong QY (2011). Brain anatomical abnormalities in high-risk individuals, first-episode, and chronic schizophrenia: an activation likelihood estimation meta-analysis of illness progression. Schizophr Bull 37: 177-188.

Christoffel DJ, Golden SA, Dumitriu D, Robison AJ, Janssen WG, Ahn HF et al (2011). IkappaB kinase regulates social defeat stress-induced synaptic and behavioral plasticity. J Neurosci 31: 314-321.

Colantuoni C, Lipska BK, Ye T, Hyde TM, Tao R, Leek JT et al (2011). Temporal dynamics and genetic control of transcription in the human prefrontal cortex. Nature 478: 519-523.

Dash PK, Orsi SA, Moore AN (2005). Sequestration of serum response factor in the hippocampus impairs long-term spatial memory. J Neurochem 93: 269-278.

Dean B (2011). Understanding the role of inflammatory-related pathways in the pathophysiology and treatment of psychiatric disorders: evidence from human peripheral studies and CNS studies. Int J Neuropsychopharmacol 14: 997-1012.

Denis-Donini S, Dellarole A, Crociara P, Francese MT, Bortolotto $\mathrm{V}$, Quadrato $\mathrm{G}$ et al (2008). Impaired adult neurogenesis associated with short-term memory defects in NF-kappaB p50deficient mice. J Neurosci 28: 3911-3919.

Ellison-Wright I, Glahn DC, Laird AR, Thelen SM, Bullmore E (2008). The anatomy of first-episode and chronic schizophrenia: an anatomical likelihood estimation meta-analysis. $\mathrm{Am} \mathrm{J}$ Psychiatry 165: 1015-1023.

Fagerlund R, Kinnunen L, Kohler M, Julkunen I, Melen K (2005). NF- $\{$ kappa\}B is transported into the nucleus by importin \{alpha\}3 and importin \{alpha\}4. J Biol Chem 280: 15942-15951.

Freudenthal R, Boccia MM, Acosta GB, Blake MG, Merlo E, Baratti $\mathrm{CM}$ et al (2005). NF-kappaB transcription factor is required for inhibitory avoidance long-term memory in mice. Eur J Neurosci 21: $2845-2852$.

Friedman JI, Tang C, Carpenter D, Buchsbaum M, Schmeidler J, Flanagan L et al (2008). Diffusion tensor imaging findings in first-episode and chronic schizophrenia patients. $\mathrm{Am} \mathrm{J}$ Psychiatry 165: 1024-1032. 
Gavalda N, Gutierrez H, Davies AM (2009). Developmental regulation of sensory neurite growth by the tumor necrosis factor superfamily member LIGHT. J Neurosci 29: 1599-1607.

Gutierrez H, Davies AM (2011). Regulation of neural process growth, elaboration and structural plasticity by NF-kappaB. Trends Neurosci 34: 316-325.

Hashimoto R, Ohi K, Yasuda Y, Fukumoto M, Yamamori H, Takahashi $\mathrm{H}$ et al (2011). Variants of the RELA gene are associated with schizophrenia and their startle responses. Neuropsychopharmacology 36: 1921-1931.

Javitt DC, Schoepp D, Kalivas PW, Volkow ND, Zarate C, Merchant $\mathrm{K}$ et al (2011). Translating glutamate: from pathophysiology to treatment. Sci Transl Med 3, $102 \mathrm{mr} 102$.

Koo JW, Russo SJ, Ferguson D, Nestler EJ, Duman RS (2010). Nuclear factor-kappaB is a critical mediator of stress-impaired neurogenesis and depressive behavior. Proc Natl Acad Sci USA 107: 2669-2674.

Li J, Gu X, Ma Y, Calicchio ML, Kong D, Teng YD et al (2010). Nna1 mediates Purkinje cell dendritic development via lysyl oxidase propeptide and NF-kappaB signaling. Neuron 68: 45-60.

Li Q, Estepa G, Memet S, Israel A, Verma IM (2000). Complete lack of NF-kappaB activity in IKK1 and IKK2 double-deficient mice: additional defect in neurulation. Genes Dev 14: 1729-1733.

Mindorff EN, O'Keefe DD, Labbe A, Yang JP, Ou Y, Yoshikawa S et al (2007). A gain-of-function screen for genes that influence axon guidance identifies the NF-kappaB protein dorsal and reveals a requirement for the kinase Pelle in Drosophila photoreceptor axon targeting. Genetics 176: 2247-2263.

Nickols JC, Valentine W, Kanwal S, Carter BD (2003). Activation of the transcription factor NF-kappaB in Schwann cells is required for peripheral myelin formation. Nat Neurosci 6: 161-167.

Patterson N, Price AL, Reich D (2006). Population structure and eigenanalysis. PLoS Genet 2: e190.

Perkins ND (2007). Integrating cell-signalling pathways with NFkappaB and IKK function. Nat Rev Mol Cell Biol 8: 49-62.

Perry RB, Fainzilber M (2009). Nuclear transport factors in neuronal function. Semin Cell Dev Biol 20: 600-606.

Post A, Rucker M, Ohl F, Uhr M, Holsboer F, Almeida OF et al (2002). Mechanisms underlying the protective potential of alphatocopherol (vitamin E) against haloperidol-associated neurotoxicity. Neuropsychopharmacology 26: 397-407.

Price AL, Patterson NJ, Plenge RM, Weinblatt ME, Shadick NA, Reich D (2006). Principal components analysis corrects for stratification in genome-wide association studies. Nat Genet 38: 904-909.

Renard P, Ernest I, Houbion A, Art M, Le Calvez H, Raes M et al (2001). Development of a sensitive multi-well colorimetric assay for active NFkappaB. Nucleic Acids Res 29: E21.

Ripke S, Sanders AR, Kendler KS, Levinson DF, Sklar P, Holmans PA et al (2011). Genome-wide association study identifies five new schizophrenia loci. Nat Genet 43: 969-976.

Roussos P, Giakoumaki SG, Adamaki E, Bitsios P (2011a). The influence of schizophrenia-related neuregulin-1 polymorphisms on sensorimotor gating in healthy males. Biol Psychiatry 69: 479-486.

Roussos P, Giakoumaki SG, Adamaki E, Georgakopoulos A, Robakis NK, Bitsios P (2011b). The association of schizophrenia risk D-amino acid oxidase polymorphisms with sensorimotor gating, working memory and personality in healthy males. Neuropsychopharmacology 36: 1677-1688.
Roussos P, Giakoumaki SG, Bitsios P (2008a). The dopamine D(3) receptor Ser9Gly polymorphism modulates prepulse inhibition of the acoustic startle reflex. Biol Psychiatry 64: 235-240.

Roussos P, Giakoumaki SG, Bitsios P (2009). A risk PRODH haplotype affects sensorimotor gating, memory, schizotypy, and anxiety in healthy male subjects. Biol Psychiatry 65: 1063-1070.

Roussos P, Giakoumaki SG, Rogdaki M, Pavlakis S, Frangou S, Bitsios P (2008b). Prepulse inhibition of the startle reflex depends on the catechol O-methyltransferase Val158Met gene polymorphism. Psychol Med 38: 1651-1658.

Roussos P, Katsel P, Davis KL, Bitsios P, Giakoumaki SG, Jogia J et al (2012a). Molecular and genetic evidence for abnormalities in the nodes of Ranvier in schizophrenia. Arch Gen Psychiatry 69: 7-15.

Roussos P, Katsel P, Davis KL, Siever L, Haroutunian V (2012b). A system level transcriptomic analysis in schizophrenia postmortem brain. Arch Gen Psychiatry 6: 1-11.

Russo SJ, Wilkinson MB, Mazei-Robison MS, Dietz DM, Maze I, Krishnan V et al (2009). Nuclear factor kappa B signaling regulates neuronal morphology and cocaine reward. J Neurosci 29: 3529-3537.

Salama-Cohen P, Arevalo MA, Meier J, Grantyn R, RodriguezTebar A (2005). NGF controls dendrite development in hippocampal neurons by binding to p75NTR and modulating the cellular targets of Notch. Mol Biol Cell 16: 339-347.

Saldana M, Bonastre M, Aguilar E, Marin C (2006). Role of nigral NFkappaB p50 and p65 subunit expression in haloperidolinduced neurotoxicity and stereotyped behavior in rats. Eur Neuropsychopharmacol 16: 491-497.

Salisbury DF, Shenton ME, Griggs CB, Bonner-Jackson A, McCarley RW (2002). Mismatch negativity in chronic schizophrenia and first-episode schizophrenia. Arch Gen Psychiatry 59: 686-694.

Sanchez-Ponce D, Tapia M, Munoz A, Garrido JJ (2008). New role of IKK alpha/beta phosphorylated I kappa B alpha in axon outgrowth and axon initial segment development. Mol Cell Neurosci 37: 832-844.

Schadt EE, Molony C, Chudin E, Hao K, Yang X, Lum PY et al (2008). Mapping the genetic architecture of gene expression in human liver. PLoS Biol 6: e107.

Song XQ, Lv LX, Li WQ, Hao YH, Zhao JP (2009). The interaction of nuclear factor-kappa B and cytokines is associated with schizophrenia. Biol Psychiatry 65: 481-488.

Sun J, Jia P, Fanous AH, van den Oord E, Chen X, Riley BP et al (2010). Schizophrenia gene networks and pathways and their applications for novel candidate gene selection. PLoS One 5: e11351.

Vallabhapurapu S, Karin M (2009). Regulation and function of NFkappaB transcription factors in the immune system. Annu Rev Immunol 27: 693-733.

Watanabe Y, Someya T, Nawa H (2010). Cytokine hypothesis of schizophrenia pathogenesis: evidence from human studies and animal models. Psychiatry Clin Neurosci 64: 217-230.

Yeh SH, Lin CH, Lee CF, Gean PW (2002). A requirement of nuclear factor-kappaB activation in fear-potentiated startle. J Biol Chem 277: 46720-46729.

Young KM, Bartlett PF, Coulson EJ (2006). Neural progenitor number is regulated by nuclear factor-kappaB p65 and p50 subunit-dependent proliferation rather than cell survival. J Neurosci Res 83: 39-49.

Supplementary Information accompanies the paper on the Neuropsychopharmacology website (http://www.nature.com/npp) 